\title{
Does the SARB Respond to Oil Price Movements? Historical Evidence from the
}

Frequency Domain

\author{
G. C. Aye ${ }^{1}$, O.A. Gadinabokao ${ }^{1}$, R. Gupta ${ }^{1}$ \\ ${ }^{1}$ Department of Economics, University of Pretoria, 0002, Pretoria, South Africa \\ Address Correspondence to R. Gupta, ${ }^{1}$ Department of Economics, University of Pretoria, 0002, Pretoria, South Africa. E-mail: \\ rangan.gupta@up.ac.za
}

\section{Running Head: Oil prices and interest rate}

\begin{abstract}
Causality testing procedures in the frequency domain and the time domain are employed to analyse the relationship between oil prices and interest rate in South Africa, covering the time period 1936:1 to 2013:11. Results show that the time domain Granger causality test fails to reject the null hypothesis for the full-sample, and the test rejects the null hypothesis for the 3rd sub-sample (1998:12-2013:11), following structural break tests. Results for the frequency domain causality test show that, for both of these samples the null hypothesis is rejected at certain frequencies; at higher frequencies for the full sample, and at lower frequencies for the 3rd sample. With the majority of the 3rd sub-sample period coinciding with inflation targeting regime, results highlight that the South African Reserve Bank (SARB) seems to have systematically responded to oil price shocks.
\end{abstract}

Key words: Oil prices; Interest rate; Frequency domain causality test; South Africa

\section{INTRODUCTION}

The transmission channels through which oil price shocks may have an impact on interest rates have been discussed in the literature (Brown and Yücel, 2002; Pierce and Enzler, 1974; 
Mork, 1994; Tang et.al, 2009; Doğrul and Soytas, 2010). The first is the classical supply shock. Rising prices can be indicative of a supply-side shock that reduces output, signalling the reduced availability of an input to production. Productivity slows down which lessens the real wage and increases the unemployment rate where inflation accelerates. If the consumers expect the near-term effects on output to be greater than the long-term effects, they will attempt to smooth out their consumption by saving less or borrowing more which boosts the equilibrium interest rate. Therefore rising oil prices reduce GDP growth by reducing the production and hence the output, which results in a boost to the real interest rate and the measured inflation rate.

The second is the inflation effect which establishes a relationship between the domestic inflation and oil prices. When the observed inflation is caused by cost shocks including oil price increases, contractionary monetary policy may deteriorate long-term output by increasing interest rate and decreasing investment. The third channel which was also discussed by Pierce and Enzler (1974) and Mork (1994) is the real balance effect. According to this transmission channel, increase in oil prices would lead to an increase in money demand. When monetary authorities fail to increase money supply to meet growing demand, the interest rate will rise deteriorating the growth rate. A fourth channel is the wealth transfer (or the income transfers and aggregate demand) effect, emphasizing the shift in purchasing power from oil importing nations to oil-exporting nations that results from rising oil prices. The shift in the purchasing power leads to a reduction in consumer demand in the oil-importing nations and increases consumer demand in the oil-exporting nations. Consequently, world consumer demand for goods produced in oil-importing nations is reduced and the world supply of savings is increased (Doğrul and Soytas, 2010). The increase in the supply of saving puts downward pressure on the interest rate, which stimulates 
investment that offsets the reduction in consumption and leaves aggregate demand unchanged in oil importing economies.

Empirically, the relationship between the oil prices and interest rate has been investigated (See Reicher and Utlaut, 2010; Eryğit, 2012; Arora and Tanner, 2011; Akram, 2009; Gronwald, 2009; Fofona et.al, 2009; Gupta and Kanda, 2014; Essama-Nssah et.al, 2007; Gupta and Modise, 2013). In this study we employ a causality testing procedure in the frequency domain to analyse the relationship between real oil prices and interest rates in South Africa. This is because, the standard Granger causality test in the time domain cannot decompose causality at different time horizons or frequencies, and hence is not capable of distinguishing between short-run and long-run causality (Gupta et al., 2013). South Africa being an oil-importing developing country makes this study interesting since the adverse economic impact of high oil prices on oil-importing developing countries is generally more severe than the impact on developed countries (Aydin and Acar, 2011). Although interest rate has been included in recent South African studies as part of a number of variables to analyse its relationship with oil prices, very few have focused on the relationship between oil prices and interest rates as a case. Moreover, none of the previous studies analysed the causal relationship between the two series. Our methodology also assists us in investigating the impact of oil prices on interest rate for South Africa at different frequencies. The only known closely related study to ours is that of Gronwald (2009) for the German economy. However, our study uses a much longer data sample (1936:1-2013:11) than his, a period which includes the most recent global financial and economic crisis. Moreover, given the length of our sample period we implement not only the full sample frequency domain as in (Gronwald, 2009), but also sub-sample frequency domain analysis to account for structural breaks, which are detected at 1984:9 and 1998:12. 
The rest of the paper is divided as follows, the next section discusses the methodology, the third section discusses the data and results, while the fourth section concludes.

\section{METHODOLOGY}

The frequency domain causality test is employed. The frequency domain causality test, which is based on the frameworks of Geweke (1982) and Hosoya (1991) was developed by Breitung and Candelon (2006). The test is presented in a two-dimensional vector time series $Z_{t}=\left(X_{t}, Y_{t}\right)$ observed at time $t=1, \ldots, T$, where $Z_{t}$ is a finite-order VAR process of the form:

$$
\Theta(B) Z_{t}=\varepsilon_{t}, \quad t=1,2, \ldots
$$

where $\Theta(B)=1-\theta_{1} B-\ldots-\theta_{p} B^{p}$ is a $2 \times 2$ lag polynomial with $B^{k} Z_{t}=Z_{t-k}$. The error vector $\varepsilon_{t}$ is a white noise process, with $E\left(\varepsilon_{t}\right)=0$ and $E\left(\varepsilon_{t} \varepsilon_{t}^{\prime}\right)=\Sigma$, where $\Sigma$ is a positive definite variance matrix. The VAR process may include a constant, trend or dummy variables. The matrix $\Sigma$ is then decomposed as $G^{\prime} G=\Sigma^{-1}$ where $G$ is the lower triangular matrix of the Cholesky decomposition. With the assumption that the system is stationary, the moving average (MA) representation is,

$$
\mathrm{Z}_{\mathrm{t}}=\Phi(\mathrm{B}) \varepsilon_{\mathrm{t}}=\left(\begin{array}{ll}
\phi_{11}(\mathrm{~B}) & \phi_{12}(\mathrm{~B}) \\
\phi_{21}(\mathrm{~B}) & \phi_{22}(\mathrm{~B})
\end{array}\right)\left(\begin{array}{l}
\varepsilon_{1 \mathrm{t}} \\
\varepsilon_{2 \mathrm{t}}
\end{array}\right)=\left(\begin{array}{ll}
\psi_{11}(\mathrm{~B}) & \psi_{12}(\mathrm{~B}) \\
\psi_{21}(\mathrm{~B}) & \psi_{22}(\mathrm{~B})
\end{array}\right)\left(\begin{array}{l}
\xi_{1 \mathrm{t}} \\
\xi_{2 \mathrm{t}}
\end{array}\right)=\Psi(\mathrm{B}) \xi_{\mathrm{t}}
$$

where $\Psi(B)=\Phi(B) G^{-1}$. Then, the spectral density of $X_{t}$ is expressed as:

$$
f_{x}(\omega)=\frac{1}{2 \pi}\left[\left|\psi_{11}\left(e^{-i \omega}\right)\right|^{2}+\left|\psi_{12}\left(e^{-i \omega}\right)\right|^{2}\right]
$$

Geweke (1982) and Hosoya (1991) suggest using the measure of causality defined as,

$$
\mathrm{M}_{\mathrm{Y} \rightarrow \mathrm{X}}(\omega)=\log \left[1+\frac{2 \pi \mathrm{f}_{\mathrm{X}}(\omega)}{\left|\psi_{11}\left(\mathrm{e}^{-\mathrm{i} \omega}\right)\right|^{2}}\right]
$$

Plugging now (3) into (4) gives, 


$$
\mathrm{M}_{\mathrm{Y} \rightarrow \mathrm{X}}(\omega)=\log \left[1+\frac{\left|\psi_{12}\left(\mathrm{e}^{-\mathrm{i} \omega}\right)\right|^{2}}{\left|\psi_{11}\left(\mathrm{e}^{-\mathrm{i} \omega}\right)\right|^{2}}\right]
$$

Equation (5) is zero if $\left|\psi_{12}\left(\mathrm{e}^{-\mathrm{i} \omega}\right)\right|^{2}=0$, which implies that $\mathrm{Y}$ does not Granger-cause $\mathrm{X}$ at frequency $\omega$.

The null hypothesis that $\mathrm{Y}$ does not Granger-cause $\mathrm{X}$ at frequency $\omega$ is then given as

$$
\mathrm{H}_{0}: \mathrm{M}_{\mathrm{Y} \rightarrow \mathrm{X}}(\omega)=0 .
$$

The statistic $M_{Y \rightarrow X}(\omega)$ is then obtained by replacing $\left|\psi_{11}\left(e^{-i \omega}\right)\right|$ and $\left|\psi_{12}\left(e^{-i \omega}\right)\right|$ in (5) by the estimated values obtained from the fitted VAR.

\section{DATA AND EMPIRICAL FINDINGS}

Monthly data on the Western Texas Intermediate crude oil spot price and the South African 91 days Treasury bill rate (TBILL) covering the period 1936:1 to 2013:12 is used. The data was obtained from the Global Financial database. The oil price series is deflated by US CPI to obtain real oil price (OILP), also obtained from the Global Financial database.

Prior to the investigation of causality between the two variables, we run three different unit root tests in order to assess the stationarity properties of the variables and these include the Augmented Dickey Fuller test (ADF), Dickey-Fuller Generalised Least (DFGLS) as well as the Phillips Perron test (PP) for the case of intercept, and intercept and trend. All the unit root tests as reported in Table 1 fail to reject the null hypothesis of a unit root in both OILP and TBILL at levels with the exception of the DF-GLS test which rejected the null at 5\% significance level for OILP for the case of intercept only, but cannot reject the null at $1 \%$ level. However, the null hypothesis cannot be rejected for the first differences of both series. Therefore, we conclude that both OILP and TBILL are integrated of order one, i.e. $\mathrm{I}(1)$. 
TABLE 1

Unit Root Tests

\begin{tabular}{|c|c|c|c|c|c|c|c|}
\hline & & \multicolumn{3}{|c|}{ Intercept } & \multicolumn{3}{|c|}{ Intercept \& Trend } \\
\hline & & Level & $\begin{array}{c}\text { First } \\
\text { Difference }\end{array}$ & Decision & Level & $\begin{array}{c}\text { First } \\
\text { Difference }\end{array}$ & Decision \\
\hline \multirow{3}{*}{$\ln ($ OILP) } & ADF & -2.115 & -21.824 & $\mathrm{I}(1)$ & -2.897 & -21.832 & $\mathrm{I}(1)$ \\
\hline & DF-GLS & -2.140 & -4.173 & $\mathrm{I}(0)$ & -2.323 & -19.332 & I(1) \\
\hline & PP & -1.787 & -20.833 & I(1) & -2.542 & -20.816 & $\mathrm{I}(1)$ \\
\hline \multirow{3}{*}{$\ln ($ TBILL) } & ADF & -1.663 & -19.456 & $\mathrm{I}(1)$ & -1.064 & -19.506 & I(1) \\
\hline & DF-GLS & -0.141 & -19.440 & I(1) & -1.221 & -19.445 & I(1) \\
\hline & $\mathrm{PP}$ & -1.710 & -20.841 & $\mathrm{I}(1)$ & -1.378 & -20.830 & $\mathrm{I}(1)$ \\
\hline
\end{tabular}

Note: critical values:

- Intercept: $-3.437,-2.864,-2.568(-2.564,-1.941,-1.616)$ for ADF and PP (ADF-GLS) at $1 \%, 5 \%$ and $10 \%$ level of significance respectively.

- Intercept \& Trend: $-3.967,-3.414,-3.129(-3.480,-2.890,-2.570)$ for ADF and PP (ADF-GLS) at $1 \%, 5 \%$ and $10 \%$ level of significance respectively.

In order to determine whether oil prices and interest rate are cointegrated, we perform the Johansen (1988) cointegration test on the variables. Results show that there is no cointegration between real oil prices and interest rate and therefore these variables do not have a long-run relationship. ${ }^{1}$ Next we test for the causal relationship between the real oil prices and interest rate. We first use the Granger causality test in the time domain and test for causality for the entire sample. The optimal lag length is 7 based on the Akaike Information Criteria (AIC). From Table 2 we observe that the null hypothesis that "real oil prices do not cause the treasury bill rate" is not rejected at any conventional level of significance for the entire sample. This implies that real oil price did not have predictive content for interest rate for the entire period. Given that we use a long-span of data, there is the possibility that the relationship between the two variables may encounter structural breaks. In order to check for

\footnotetext{
${ }^{1}$ The results are available from authors upon request.
} 


\section{TABLE 2}

\section{Time- Domain Granger Causality Test}

\begin{tabular}{llr}
\hline Sample & Test Statis tic & p-value \\
\hline $1936: 2-2013: 11$ & $9.339987[7]$ & 0.2292 \\
$1936: 2-1984: 8$ & $3.629688[5]$ & 0.6039 \\
$1984: 9-1998: 11$ & $3.438163[7]$ & 0.8417 \\
$1998: 12-2011: 11$ & $12.12768[3]$ & 0.007 \\
\hline
\end{tabular}

possible structural breaks we perform the Bai and Perron (2003) sequential and repartition tests to the equation:

$$
d(\ln T B I L L)=c+\sum_{i=1}^{p} d(\ln T B I L L)_{t-1}+\sum_{i=1}^{p} d(\ln O I L P)_{t-i}+\varepsilon_{t}
$$

and we detect structural breaks at $1984: 9$ and 1998:12. Therefore, we perform the time domain Granger causality test over three sub-samples: 1936:2 - 1984:8, 1984:9 - 1998:11, 1998:12 - 2013:11. The lag length for each of the sub-samples is based on the AIC. The null hypothesis is rejected at the conventional level of 5\% for the last sub-sample (1998:122013:12) only. The null hypothesis of non-causality between the two variables is not rejected for both the first and second sub-samples.

We then apply the frequency domain causality test developed by Breitung and Candelon (2006) in order to assess whether real oil prices cause the interest rate. It permits the decomposition of the causality test statistics into different frequencies. The test is applied to the full sample as well as the three sub-samples used in the time domain Granger causality test with the same lag structure used previously. The results are depicted in Figures 1 to 4 . The test statistics are represented by the solid line along with their $5 \%$ critical values in the form of a broken line for all frequencies in the interval $(0, \pi)$. For the full sample $(1936: 2-$ 
2013:11) as presented in Figure 1, the null hypothesis that real oil price does not cause interest rate is rejected for $\omega$ between 2.15 and 2.45 implying a cycle of 2.56 to 2.92 months (the frequency $\omega$ can be translated into a cycle or periodicity of T months by $T=2(\pi / \omega)$ where $\mathrm{T}$ is the period). For the sub-samples (1936:2 - 1984:8) in Figure 2 as well as (1984:9 - 1998:11) in Figure 3, the null hypothesis is not rejected for any frequencies. For the final sample (1998:12 - 2013:11) in Figure 4, the null hypothesis is rejected for $\omega$ between 0 and 1.85 implying a cycle of 3.4 months and above.

FIGURE 1

Frequency Domain Causality (1936:2 - 2013:12)

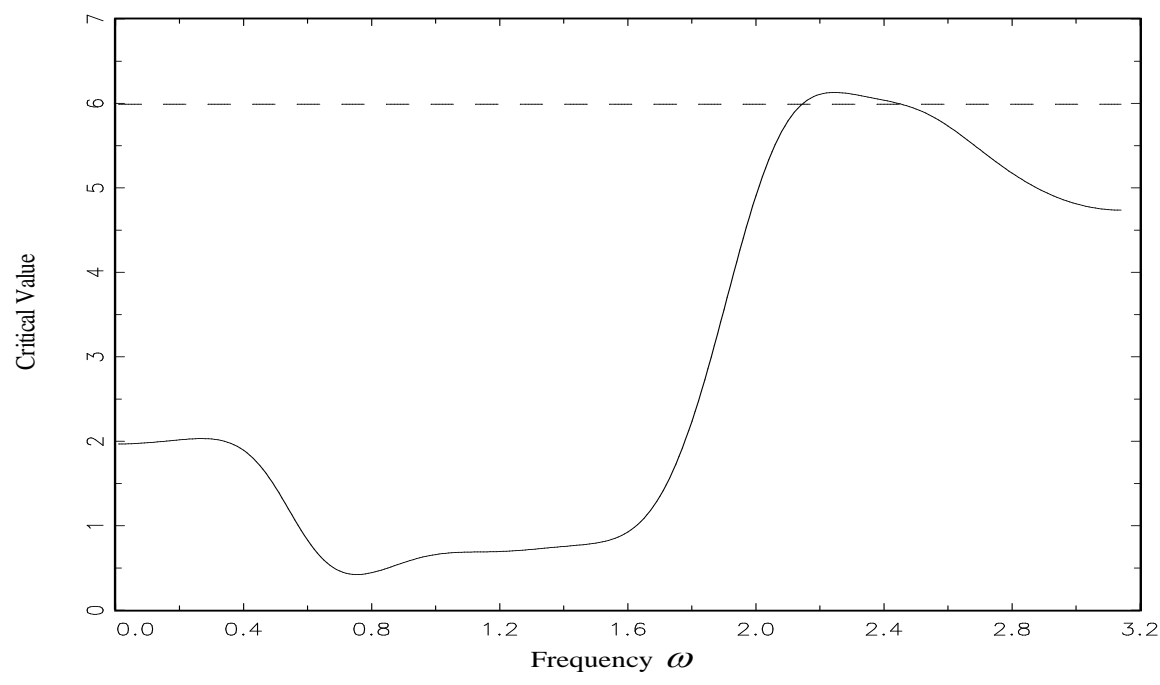


FIGURE 2

Frequency Domain Causality (1936:2 - 1984:8)

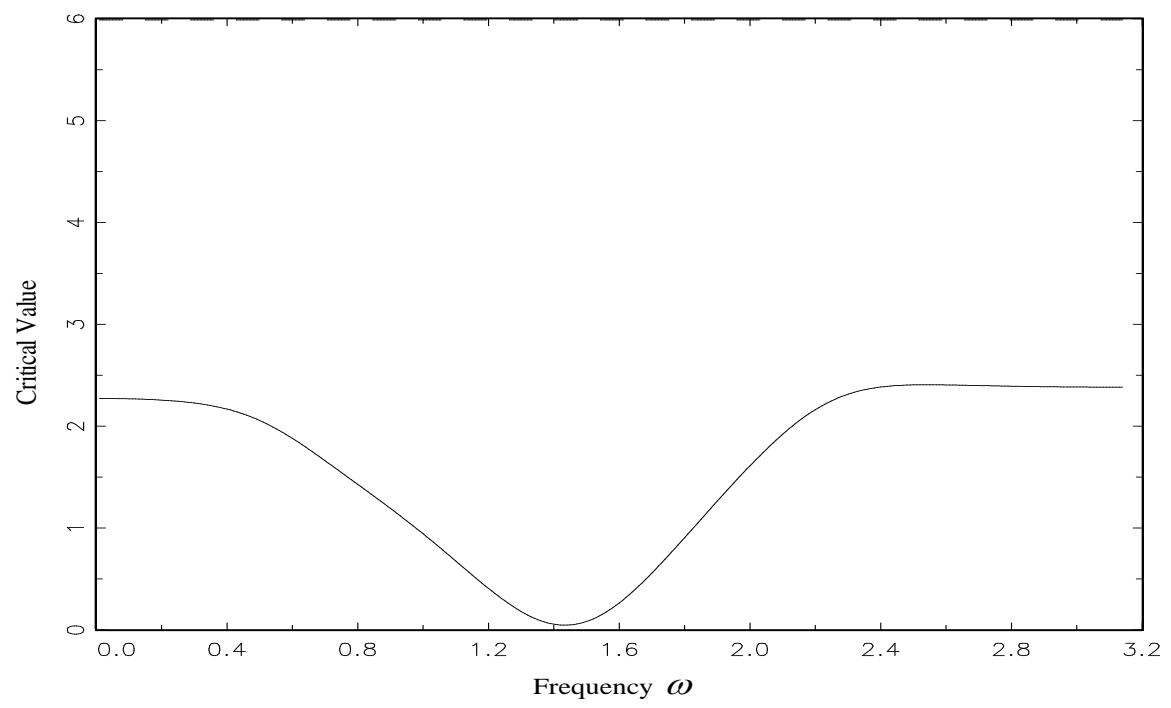

FIGURE 3

Frequency Domain Causality (1984:9 - 1998:11)

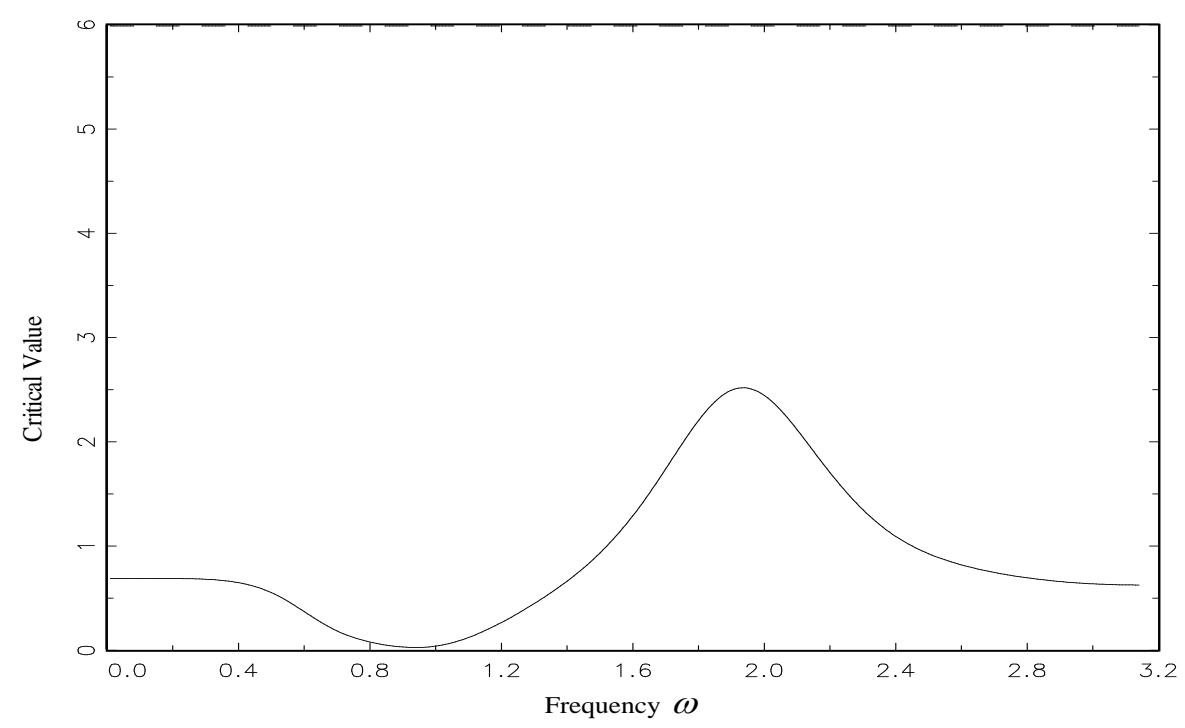




\section{FIGURE 4}

Frequency Domain Causality (1998:12 - 2013:11)

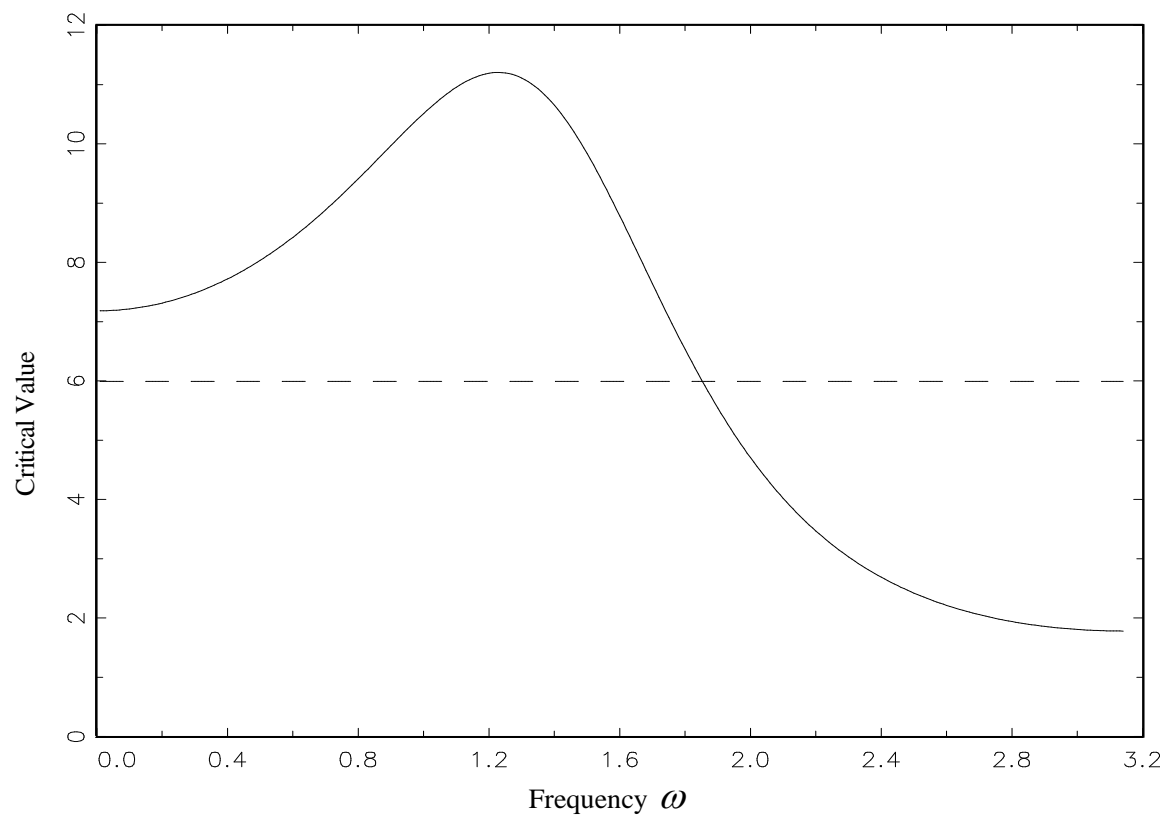

Comparing these results for the two different tests we observe the following: as in the time domain Granger causality test, the frequency domain test also fails to reject the null hypothesis that "real oil prices cause treasury bill rate" for the $1^{\text {st }}$ and $2^{\text {nd }}$ sub-samples. The time domain Granger causality test fails to reject the null hypothesis for the full-sample and marginally rejects the null hypothesis for the $3^{\text {rd }}$ sub-sample. The results for the frequency domain causality test are different, in that the null hypothesis is rejected at specific frequencies for both the full sample and $3^{\text {rd }}$ sub-sample. The null hypothesis is rejected at higher frequencies (shorter cycle lengths) for the full sample and at shorter frequencies (longer cycle lengths) for the $3^{\text {rd }}$ sub-sample. This implies that real oil prices have a causal link with the interest rate at short and long cycle lengths for the case of South Africa. In light of this, the importance of the frequency domain causality is noted as it allows us to 
decompose causality by different frequencies and consequently detect causality at certain cycle lengths even when the time domain causality might fail to pick it up.

\section{CONCLUSION}

This paper examines whether a causal relationship exists between real oil prices and interest rate in a developing country -South Africa. We employ a causality testing procedure in the frequency domain to analyse the relationship between these variables. The results revealed that the time domain Granger causality test fails to reject the null hypothesis for the fullsample (1936:1 - 2013:11), but strongly rejects the null hypothesis for the $3^{\text {rd }}$ sub-sample (1998:12 - 2013:11) detected post tests of structural breaks. The results for the frequency domain causality test are different, in that the null hypothesis is rejected at certain frequencies for both the full sample and $3^{\text {rd }}$ sub-sample. This implies that oil prices have a causal link with interest rate at shorter and longer cycle lengths for the case of South Africa, with stronger causality in the third sub-sample - with the majority of this period coinciding with inflation targeting period, highlighting that the South African Reserve Bank seems to have systematically responded to oil price shocks, especially over the inflation targeting period of 2000:2 and onwards. Further, our results indicate the importance of the frequency domain causality as it allows us to decompose causality by different frequencies and consequently detect causality at certain cycle lengths even when the time domain causality might fail pick it up.

\section{REFERENCES}

Akram, Q.F. 2009. Commodity prices, interest rates and the dollar. Energy Economics

31(6):838-851.

Arora, V., Tanner, M. 2011. How important are real interest rates for oil prices? Munich 
Personal RePEc Archive 35883.

Aydin, L., Acar, M. 2011. Economic impact of oil price shocks on the Turkish economy in the coming decades: A dynamic CGE analysis. Energy Policy 39(3):1722-1731.

Bai, J., Perron, P. 2003. Computation and analysis of multiple structural change models. Journal of Applied Econometric 18(1):1-22.

Breitung, J., Candelon, B. 2006. Testing for short- and long-run causality: A frequency-domain approach. Journal of Econometrics 132(2):363-378.

Brown, S.P., Yücel, M.K. 2002. Energy prices and aggregate economic activity: an interactive survey. The Quarterly Review of Economics and Finance 42(2):193-208.

Doğrul, H.G., Soytas U. 2010. Relationship between oil prices, interest rate, and unemployment: Evidence from an emerging market. Energy Economics 32:1523 -1528.

Eryğit, M. 2012. The Dynamic Relationship between oil price shocks and selected macroeonomic variables in Turkey. Economic Research 25(2):263-176.

Essama-Nssah, B., Go, D.S., Kearney, M., Korman, V., Robinson, S., Thierfelder, K., 2007. Economy-wide and Distributional Impacts of an Oil Price Shock on the South African Economy. World Bank, Washington, DC.

Fofana, I., Chitiga, M., Mabugu, R. 2009. Oil prices and the South African economy: A macro-mesomicro analysis. Energy policy 37:5509-5519.

Geweke, J. 1982. Measurement of linear dependence and feedback between multiple time series. Journal of the American Statistical Association 77:304-324.

Gronwald, M. 2009. Reconsidering the macroeconomics of oil price in Germany: Testing for causality in the frequency domain. Empirical Economics 36(2):441-453. 
Gupta, R., Kanda, P.T. 2014. Does the Price of Oil Help Predict Inflation in South Africa? Historical Evidence Using a Frequency Domain Approach. University of Pretoria, Department of Economics. Working Papers 2014-01.

Gupta, R., Gil-Alana, L.A., Yaya, O.S. 2013. Does Sunspot Numbers Cause Global Temperatures? Evidence from a Frequency Domain Causality Test. University of Pretoria, Department of Economics. Working Paper 2013-82.

Gupta, R., Modise, M. 2013. Does the source of oil price shocks matter for South African stock market returns? A structural VAR approach. Energy Economics. Energy Economics 40:825831.

Hosoya, Y. 1991. The decomposition and measurement of the interdependence between second-order stationary processes. Probability Theory and Related Fields 88: 429-444.

Johansen, S., 1988. Statistical Analysis of Cointegration Vectors. Journal of Economics Dynamics and Control 12(2-3):231-254.

Mork, K.A. 1994. Business Cycles and the oil market. The Energy Journal 15:15-38.

Pierce, J.L. Enzler, J.J. 1974. The effects of external inflationary shocks. Brookings Paper on Economic Activity 1:13-61.

Reicher, C.P., Utlaut J.F. 2010. The relationship between oil prices and long-term interest rates. Kiel Institute for the World Economy. Kiel Working Paper 1637.

Tang, W., Wu, L., Zhang, Z. X. 2009. Oil Price Shocks and Their Short- and Long- Term Effects on the Chinese Economy. East West Centre Working Paper No. 102. 